Part of Journal of Research of the National Bureau of Standards, Volume 20, June 1938

\title{
REPRODUCIBILITY OF THE SILVER-SILVER CHLORIDE ELECTRODE
}

\author{
By Edgar Reynolds Smith and John Keenan Taylor
}

\section{ABSTRACT}

A study was made of the reproducibility of the electrolytic, thermal-electrolytic, and thermal types of the silver-silver chloride electrode in $0.05 \mathrm{~N}$ solution of potassium chloride. The presence or absence of light, and of air dissolved in the solution, have no significant effect on their potentials. A marked aging effect was noted, the origin of which was traced to concentration-polarization occurring during the preparation of the electrodes. The attainment of concentration equilibrium between freshly prepared electrodes and solution is slow and may require from 1 to 20 days, depending on porosity of the electrodes and stirring of the solution. For the same reason, freshly prepared electrodes behave as cathodes towards aged electrodes, the initial difference in potential of ten exceeding a millivolt. When sufficient time is allowed for the establishment of concentration equilibrium, these types of silver-silver chloride electrodes assume the same potential, within about $0.02 \mathrm{mv}$.

CONTENTS

I. Introduction $\ldots \ldots \ldots$

II. Apparatus and materials

III. Reproducibility of the electrodes

IV. Change in potential with age

\section{INTRODUCTION}

In addition to its individual importance, the silver-silver chloride electrode is finding increasing use as a secondary reference electrode to replace the calomel half-cell. ${ }^{1}$ Many important reactions occur in chloride solutions, where this electrode can be applied directly with convenience, because of its compact solid form. Thus by its use, liquid junctions, generally a source of uncertainty in otherwise precise measurements, can often be avoided.

Among the various types of the silver-silver chloride electrode that have been proposed, there are three whose convenience of form and ease of preparation have led to their popular adoption. These particular types are electrolytic, thermal-electrolytic, and thermal. The electrolytic type ${ }^{2}$ is made by electroplating silver on a base of platinum and then forming a coating of chloride on the silver by electrolysis in a chloride solution. The platinum base may be in the form of gauze, foil, or wire. The thermal-electrolytic type ${ }^{3}$ is

'B. Wingfield, W. H. Goss, W. J. Hamer, and S. F. Acree, A STM Bul. 90, 15 (1938). W. J. Hamer, Trans. Electrochem. Soc. 72,63 (1937). C. N. Murray and S. F. Acree, BS J. Research 7, 713 (1931) RP369,

${ }_{2}^{2}$ H. Jahn, Z. physik. Chem. 33, 545 (1900). D. A. MacInnes and K. Parker, J. Am. Chem. Soc. 37, 1445 (1915). D. A. MacInnes and J. A. Beattie, J. Am. Chem. Soc. 42, 1117 (1920). A. S. Brown, J. Am. Chem. Soc. 56, 646 (1934). A. S. Brown and D. A. MacInnes, J. Am. Chem. Soc. 5\%, 1356 (1935). T. Shedlovsky and D. A. MacInnes, J. Am. Chem. Soc. 58, 1970 (1936).

${ }^{3}$ G. N. Lewis, J. Am. Chem. Soc. 28, 158 (1906). A. A. Noyes and J. H. Ellis, J. Am. Chem. Soc. 39, 2532 (1917). H. S, Harned, J. Am. Chem, Soc, 51, 416 (1929). 
prepared by heating a paste of silver oxide and water, supported on a small spiral of platinum wire, in an electric furnace at $400^{\circ} \mathrm{C}$ to convert the silver oxide to a porous globule of silver, and then electrolytically coating the silver with chloride. The thermal type ${ }^{4}$ is made by heating to decomposition in an electric furnace a paste of silver chlorate, silver oxide, and water, supported on a small spiral of platinum wire. By this method of preparation, an intimate mixture of silver and silver chloride is formed on the supporting wire by one thermal operation, without resort to electrolysis.

An examination of the literature reveals conflicting opinions and data concerning the reproducibility and constancy of the silver-silver chloride electrode. ${ }^{5}$ In this investigation a number of electrodes of the electrolytic, thermal-electrolytic, and thermal types were prepared and tested for reproducibility and constancy in the presence and absence of light, and in the presence and absence of dissolved air. Each type was tested first separately by intercomparing electrodes of the same kind and then, after conditions of reproducibility and constancy were established, the different types were compared to determine what differences might exist between the final equilibrium values of potential of each type.

\section{APPARATUS AND MATERIALS}

The measurements of electromotive force were made with a Rubicon, type B, high-precision potentiometer and an unsaturated Weston standard cell, both of which were calibrated by the Electrical Division

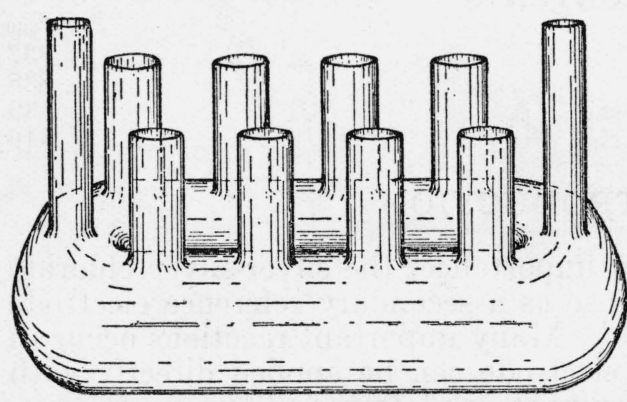

Figure 1.-Cell for comparing electrodes in airsaturated solutions with or without exclusion of light.

paint which is water-soluble but impervious to the oil of the thermostat. Another type of cell, shown in figure 2, was used to intercompare electrodes in the absence of oxygen. These cells were made from 400-ml dye beakers. A gas-bubbling jet was sealed into each, as shown in the figure, and the top was closed by a large rubber stopper through which were inserted the electrodes and a gas exit tube. To remove oxygen from the solution in these cells, nitrogen, freed from oxygen by passage through pyrogallol solution, followed by passage through a solution of the same composition as that in the cell, was bubbled through the cells.

The cells were immersed in an oil bath of 80 liters capacity, equipped with a stirrer, heater, cooling coil, and a thermoregulator. Since the

\footnotetext{
4 C. K. Rule and V. K. La Mer, J. Am. Chem. Soc. 58, 2339 (1936).

A. A. Noyes and J. H. Ellis, J. Am. Chem. Soc. 39, 2532 (1917). M. Randall and L. E. Young, J. Am. Chem. Soc. 50, 989 (1928). E. R. Smith, BS J. Research 2, 1140 (1929) RP74. W. R. Carmody, J, Am. Chem Soc. 51, 2901 (1929); 54, 188 (1932). A. S. A fanasiev, J. Am. Chem. Soc. 52, 3477 (1930).
} 
measurements to be made were of differences in potential of silversilver chloride electrodes having practically the same temperature coefficients of electromotive force, only a uniform temperature was maintained in the bath, no effort being made to secure any precisely fixed temperature. The observations reported in this paper are for room temperatures, which were within the range of 25 to $30^{\circ} \mathrm{C}$.

The leads from the cells to the potentiometer were insulated enameled copper wires supported on Bakelite insulators. To shield the electrical system, all parts, including the thermostat and the cells, rested on, or had metal supporting bases connected to copper sheeting at uniform potential. ${ }^{6}$

The chemicals used were of reagent grade, tested and found to conform to specifications adopted by the American Chemical Society. ${ }^{7}$ The potassium and sodium chlorides were further purified by recrystallization. Silver chlorate was prepared from silver oxide and chloric acid, and was recrystallized three times. Silver oxide was prepared

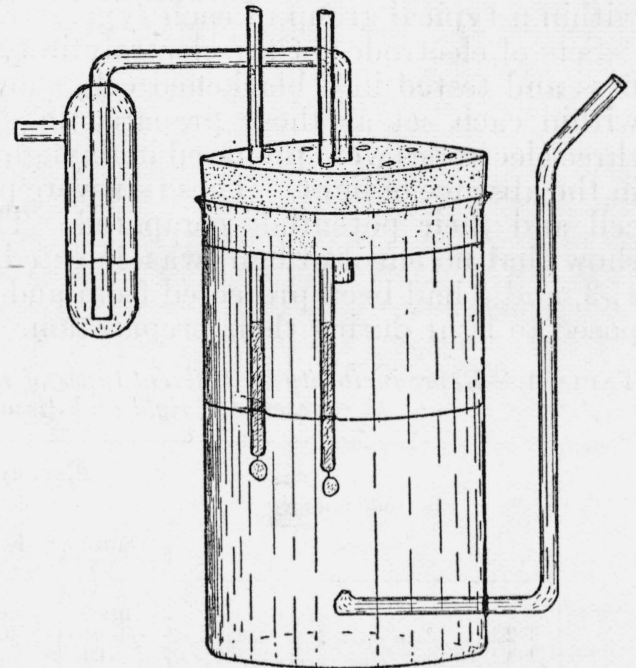

Figure 2.-Cell for comparing electrodes in oxygen-free solutions with or without exclusion of light. by adding sodium hydroxide solution to a slight excess of silver nitrate and thoroughly washing the resulting precipitate. The silver-plating solution was prepared and used essentially according to the procedure given by Brown. ${ }^{8}$

\section{REPRODUCIBILITY OF THE ELECTRODES}

Silver-silver chloride electrodes of the electrolytic type were made by welding rectangular pieces of platinum gauze, 0.5 by $1 \mathrm{~cm}$, to platinum wires which then were sealed into the ends of $6-\mathrm{cm}$ lengths of soft glass tubing. These platinum bases were cleaned by heating to brightness in a flame and then immersing them in boiling concentrated nitric acid. They were next electroplated with silver at a current of $4 \mathrm{ma}$ per electrode for 24 hours. After removal from the plating bath, they were washed in frequent changes of distilled water for a period of 10 days to remove adsorbed contaminations. ${ }^{9}$ After the washing, they were chloridized by connecting them in series as anodes in molar hydrochloric acid and passing a current of 4 to $6 \mathrm{ma}$ for 1 hour. Before transferring to the cell for measurement, they were washed first in distilled water and finally in a solution of the same composition as that in the cell. Five sets of these electrodes, having eight in each set, immersed in $0.05-N$ potassium chloride in the

6 W. P. White, J. Am. Chem. Soc. 36, 2011 (1914).

7 Ind. Eng. Chem. 17, 756 (1925); 18, 759 (1926).

A. S. Brown, J. Am. Chem. Soc. 56, 646 (1934)

W. R. Carmody, J. Am. Chem. Soc. 51, 2901 (1929). 
presence of light and dissolved air, showed an average reproducibility of $0.02 \mathrm{mv}$ within each set made at the same time. A few other sets with platinum-foil and platinum-wire bases exhibited the same degree of reproducibility. Under the same conditions, several groups of thermal-electrolytic and thermal electrodes agreed within each group with an average deviation of about $0.02 \mathrm{mv}$. These results are summarized in table 1 , where data are given of differences in potential within a typical group of each type.

Sets of electrodes of the electrolytic type, chloridized in total darkness and tested in a blackened cell, showed the same reproducibility within each set as those prepared in daylight. In one experiment three electrodes were prepared in daylight and, at the same time, three in the absence of light. These six were placed together in a blackened cell and their potentials compared. The results, given in table 2, show that no effect of light was detected. In table 2 , electrodes Nos. 1,3 , and 5 had been protected from and Nos. 2, 4, and 6 had been exposed to light during their preparation.

TABLE 1.-Reproducibility of different types of silver-silver chloride electrodes in the presence of light and dissolved air

\begin{tabular}{|c|c|c|c|c|c|}
\hline \multirow{2}{*}{ Electrode number } & \multicolumn{3}{|c|}{ Electrolytic type } & \multirow{2}{*}{$\begin{array}{l}\text { Thermal- } \\
\text { electro- } \\
\text { lytic type }\end{array}$} & \multirow{2}{*}{$\begin{array}{c}\text { Therma } \\
\text { type }\end{array}$} \\
\hline & Gauze & Foil & Wire & & \\
\hline $\begin{array}{l}1-2 \\
1-3-4 \\
1-5 \\
1-6 \\
1-8 \\
1-8\end{array}$ & $\begin{array}{r}\mathrm{mv} \\
+0.04 \\
+.00 \\
+.01 \\
+.01 \\
+.02 \\
+.03 \\
+.01\end{array}$ & $\begin{array}{c}\mathrm{mv} \\
+0.02 \\
-.01 \\
+.02 \\
+.02 \\
+.01 \\
-.01 \\
-.01\end{array}$ & $\begin{array}{c}\mathrm{mv} \\
-0.02 \\
-.02 \\
-.02 \\
-.01 \\
-.03 \\
-.04 \\
-.01\end{array}$ & $\begin{array}{c}\mathrm{mv} \\
-0.03 \\
+.01 \\
+.03 \\
+.02 \\
-.03 \\
-.04 \\
.00\end{array}$ & $\begin{array}{c}\mathrm{mv} \\
-0.04 \\
+.01 \\
.00 \\
-.03 \\
-.03 \\
-.05 \\
.00\end{array}$ \\
\hline A verage deviation.... & 0.02 & 0.02 & 0.02 & 0.02 & 0.02 \\
\hline
\end{tabular}

TABLE 2.-Comparison of electrodes, prepared in the presence and absence of light, in air-saturated solution

\begin{tabular}{|c|c|}
\hline $\begin{array}{c}\text { Electrode } \\
\text { number }\end{array}$ & $\begin{array}{c}\text { Potential } \\
\text { difference }\end{array}$ \\
\cline { 2 - 2 } & $\mathrm{mv}$ \\
$1-2$ & +0.01 \\
$1-3$ & +.01 \\
$1-4$ & -.02 \\
$1-5$ & -.02 \\
$1-6$ & +.02 \\
\hline
\end{tabular}

a Electrodes 1, 3, and 5 protected from light; 2, 4, and 6 exposed to light.

\section{CHANGE IN POTENTIAL WITH AGE}

The results cited in the previous section show that when silversilver chloride electrodes are prepared at the same time, the average agreement in potential among the individual electrodes is about $0.02 \mathrm{mv}$. However, it was found that when electrodes made at different times are compared, they may differ in potential by more than a millivolt, and that an older electrode acts as an anode with respect to a newer one. This aging effect was noted years ago by MacInnes and Parker ${ }^{10}$ who made the following interesting observation: "There was a slight aging effect noticed, the older electrodes

${ }^{10}$ D. A. MacInnes and K. Parker, J. Am. Chem. Soc. 37, 1445 (1915). 
being electropositive to the newer ones. As this effect was always in the same direction and of the same magnitude within $0.05 \mathrm{mv}$ no error arose from this source, since similar electrodes were always opposed to each other." Carmody, ${ }^{11}$ on the other hand, was unable to confirm an effect of time on the potentials of the electrodes and attributed such changes to the action of light.

Figure 3 shows the data obtained on the aging effect in the case of the electrolytic type of silver-silver chloride electrodes compared in $0.05 \mathrm{~N}$ air-saturated solution of potassium chloride without stirring. The designations $\mathrm{KCl}, \mathrm{NaCl}$, and $\mathrm{HCl}$ on the curves signify that the electrodes were chloridized in solutions of potassium chloride,

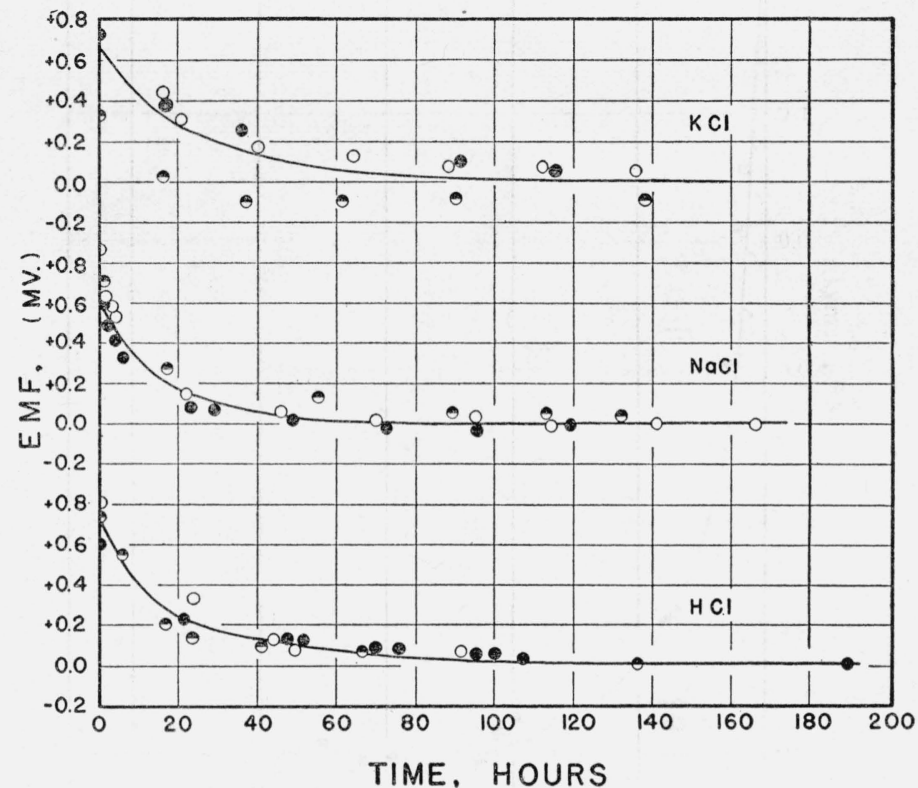

FIGURE 3.-Aging effect with the electrolytic type of silver-silver chloride electrodes in $0.05 \mathrm{~N}$ air-saturated solution of potassium chloride.

sodium chloride, and hydrochloric acid, respectively. The solution in which they were compared, however, was of potassium chloride. Each point represents the difference between the average potential of four electrodes which had been aged for at least 1 week before use and the average potential of four newer electrodes, plotted against the time in hours. Three independent sets of four newer electrodes, represented by the three different symbols, were used to determine each curve. The zero axis of time represents the time that the newer electrodes were placed in the cell, which was in general about 2 hours after they were chloridized. More than half of the total number of electrodes were measured in a cell blackened to exclude light, the data for which showed that the effect is not due to the action of light. This conclusion is substantiated also by the data given in table 2, which show that electrodes prepared and tested in the absence of light agree closely with others prepared at the same

11 W. R. Carmody, J. Am. Chem. Soc. 51, 2901 (1929), 
time in the presence of light. Accordingly, the light-protected and light-exposed electrodes change in potential with age practically to the same extent. The slopes of the curves are similar, and in every instance freshly prepared electrodes are positive, i. e., they act as cathodes with respect to aged electrodes, the difference approaching zero with time. Although the greater portion of the initial potential difference disappears during the first day, a significant difference still

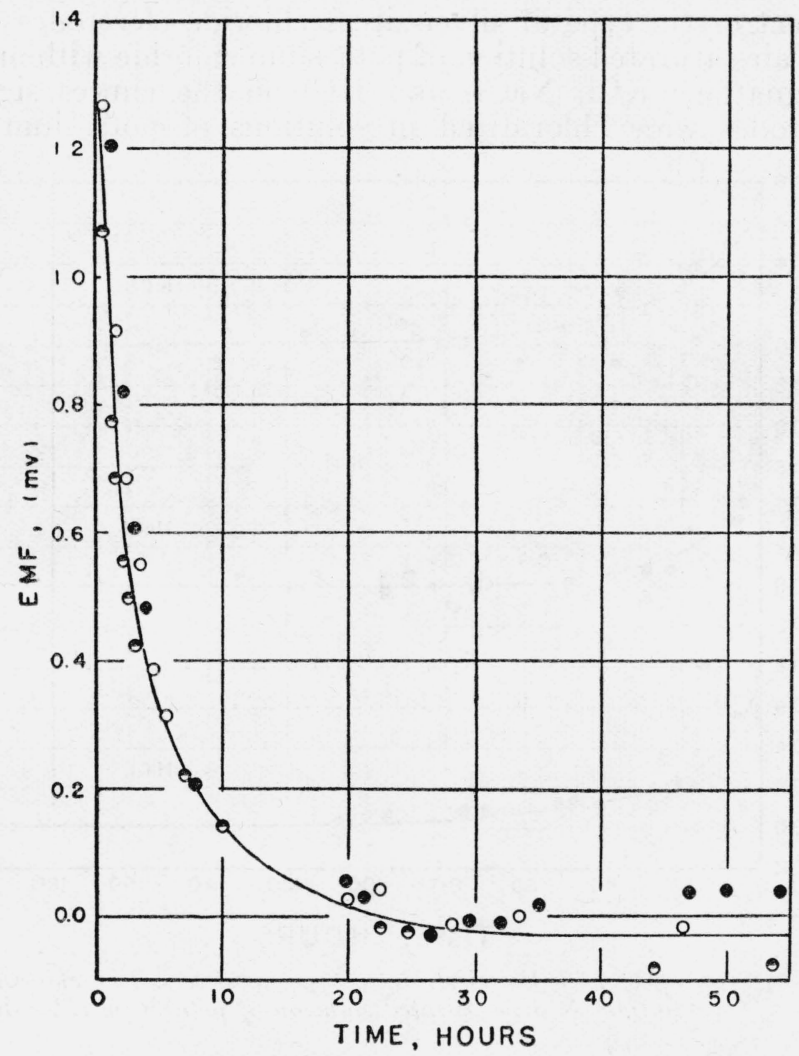

FIGURE 4.-Aging effect with the electrolytic type of silver-silver chloride electrodes in $0.05 \mathrm{~N}$ oxygen-free solution of potassium chloride.

exists for several days between the newer electrodes and those that have come to equilibrium.

To ascertain whether or not the aging effect is due to the influence of oxygen, cells of the type shown in figure 2 were used. For the electrolytic type, eight electrodes of platinum gauze electroplated with silver and a large silver-silver chloride electrode were placed in the cell containing $0.05 \mathrm{~N}$ potassium chloride solution. A current of oxygen-free nitrogen was passed through the cell and two of the silver electrodes were chloridized, using the large silver-silver chloride electrode as a cathode. In this way, the silver-silver chloride electrodes were formed without contact with oxygen and without change in the composition of the solution in the cell. After standing several days to allow the freshly formed electrodes to age, a second pair of the silver electrodes was chloridized and then compared in potential 
with the first two. On succeeding days the remaining two pairs of electrodes were chloridized and compared with the two aged electrodes. In figure 4, which shows the results obtained with the electrolytic type of electrodes, the zero axis of time was taken almost immediately

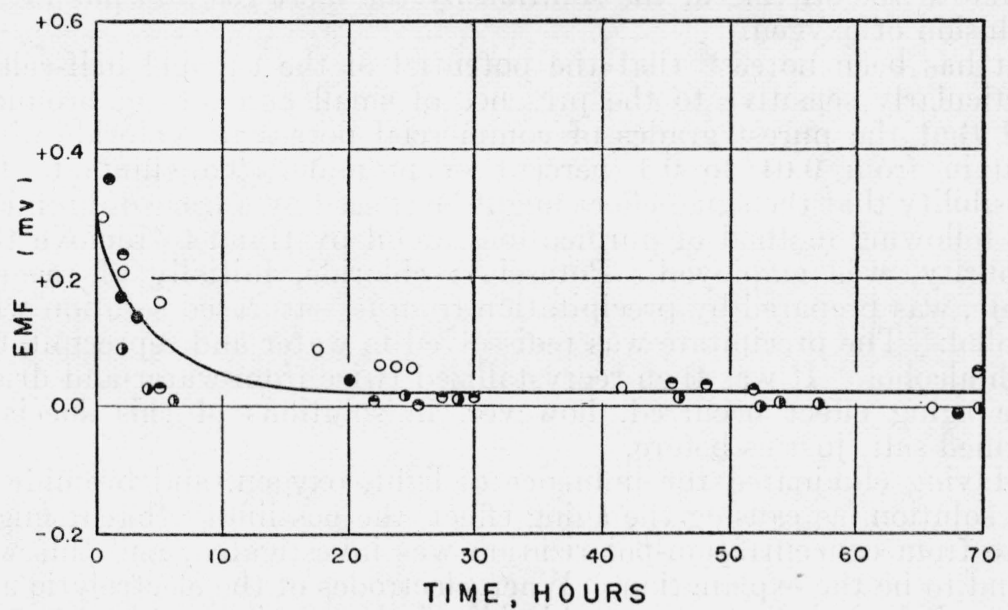

FIGURE 5.-Aging effect with the thermal-electrolytic type of silver-silver chloride electrodes in $0.05 \mathrm{~N}$ oxygen-free solution of potassium chloride.

after the electrodes were chloridized. The points on the curve represent the average values of each pair at the given time. It is seen that new electrodes are initially positive to aged electrodes by more than $1 \mathrm{mv}$. The approach to equilibrium was comparatively rapid in this case, where nitrogen was bubbled through the cell con-

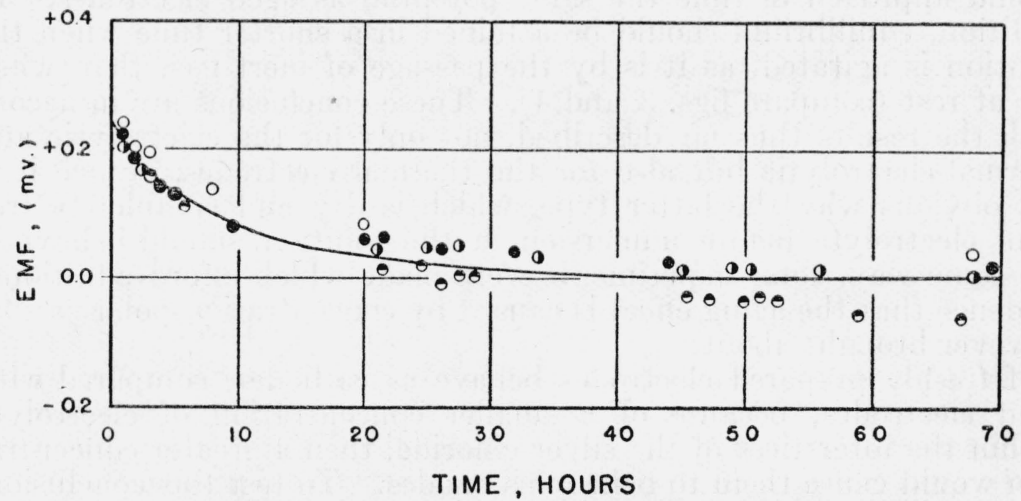

FIGURE 6.-Aging effect with the thermal type of silver-silver chloride electrodes in $0.05 \mathrm{~N}$ oxygen-free solution of potassium chloride.

tinuously except shortly before and during the times that readings were taken, and an equilibrium potential was reached after approximately 20 hours.

The aging of thermal-electrolytic and thermal electrodes was measured similarly with air excluded by the continuous passage of nitrogen through the solution. The results are shown in figure 5 (thermal-electrolytic) and figure 6 (thermal). While the over-all 
change in potential is less than in the case of the electrolytic type, the time required for attainment of equilibrium is about the same, being again more rapid with than without the passage of nitrogen through the solution. It will be seen later that this increased rate is due to the stirring of the solution by the inert gas and not to the exclusion of oxygen.

It has been noted ${ }^{12}$ that the potential of the calomel half-cell is particularly sensitive to the presence of small amounts of bromide, and that the purest grades of commercial potassium chloride often contain from 0.01 to 0.1 percent of bromide. To eliminate the possibility that the aging effect might be caused by a trace of bromide, the following method of purification, found by Hahn to remove this impurity, was employed. Potassium chloride, initially of reagent grade, was prepared by precipitation from its saturated solution with alcohol. The precipitate was redissolved in water and reprecipitated with alcohol. It was then recrystallized twice from water and dried. The aging effect occurred, however, in solutions of this specially purified salt, just as before.

Having eliminated the influence of light, oxygen, and bromide in the solution, as causing the aging effect, the possibility that it might arise from concentration-polarization was investigated, and this was found to be the explanation. When electrodes of the electrolytic and thermal-electroly tic types are chloridized, the solution within the pores of the silver chloride coating becomes more dilute than the surrounding solution, and these electrodes, freshly prepared and placed in the measuring solution at the same time should, for this reason, act as cathodes toward electrodes previously aged in the solution, with consequent replenishment of electrolyte within their pores. Also, the freshly prepared electrodes should agree among themselves, except for secondary differences arising from variations in porosity, and should approach in time the same potential as aged electrodes. In addition, equilibrium should be attained in a shorter time when the solution is agitated, as it is by the passage of inert gas, than when left at rest (compare figs. 3 and 4). These conclusions are in accord with the results thus far described, not only for the electrolytic and thermal-electrolytic but also for the thermal electrodes. Since it is not obvious why the latter type, which is dry and completely free from electrolyte before immersion in the solution, should behave in the same way, some experiments were made which afford additional evidence that the aging effect is caused by concentration-polarization, however brought about.

If freshly prepared electrodes behave as cathodes, compared with aged electrodes, because of a smaller concentration of electrolyte within the interstices of the silver chloride, then a greater concentration would cause them to behave as anodes. To test this conclusion, a current of $6 \mathrm{ma}$ was passed for 10 minutes between two thermalelectrolytic electrodes, in a set which had come to equilibrium, to produce mutually opposite concentration-polarization in them. As predicted for such concentration-polarization, the one which had been the anode during passage of the current then behaved as a cathode, and the one which had been the cathode behaved as an anode, toward the aged electrodes. With nitrogen bubbling through the solution, approximately 24 hours' time was required for these two electrodes to

12 F. L. Hahn, J. Am. Chem. Soc. 57, 2537 (1935). 
reattain equilibrium, as shown by agreement again with the aged electrodes.

Four thermally-prepared silver electrodes, two aged thermal-electrolytic silver-silver chloride electrodes and a large silver-silver chloride electrode were placed in a cell containing $0.05 \mathrm{~N}$ potassium chloride. The four silver electrodes were then chloridized, using the large silver-silver chloride electrode as a cathode. Immediately afterwards, two of these were connected as cathodes to the large electrode and a current of 5 ma was passed to each for 10 minutes. Using the two aged electrodes for reference, the potentials of the two pairs of freshly prepared and oppositely polarized electrodes were

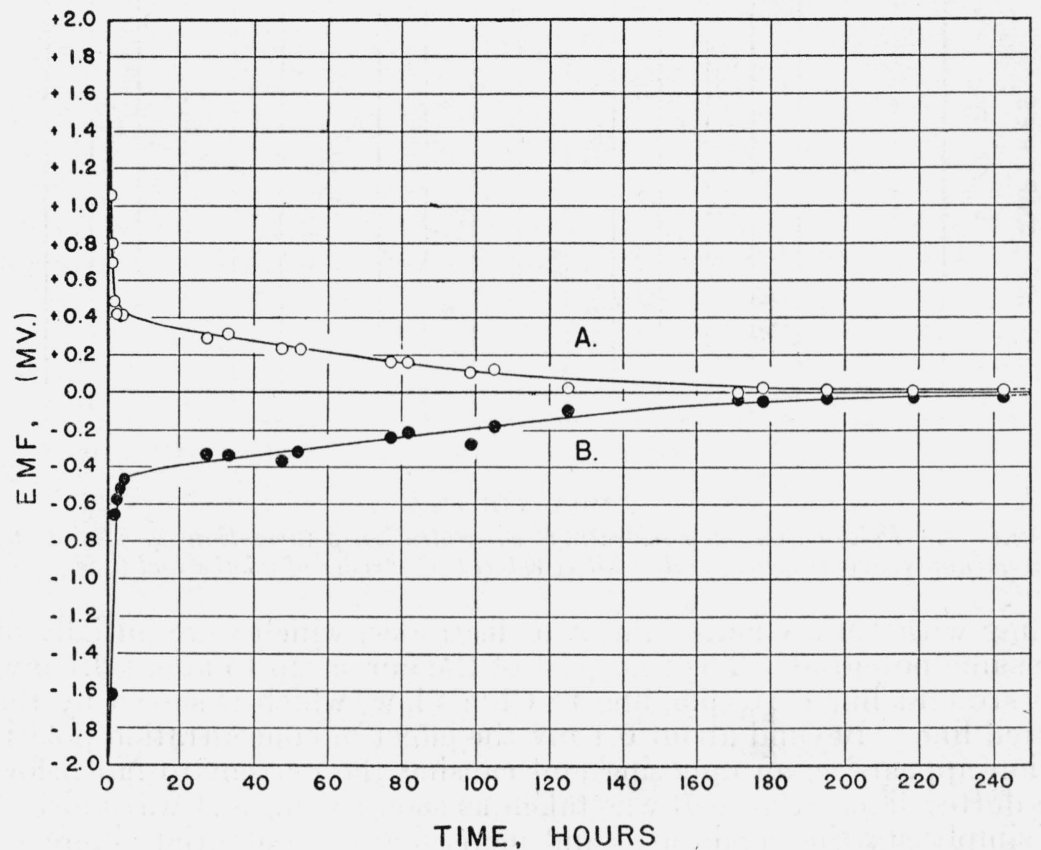

FIGURE 7.-Aging effect with oppositely polarized silver-silver chloride electrodes of the thermal-electrolytic type in $0.05 \mathrm{~N}$ potassium chloride.

compared over a period of 10 days, as shown in figure 7 . In this experiment, the solution was not stirred and, as a result, a longer time was needed for attainment of equilibrium. Curve $A$ shows the change in potential of the pair which ended their preparation as anodes, resulting in a dilution of electrolyte within the pores, and curve $B$ is for the pair which ended as cathodes, resulting in a concentration of electrolyte within the pores. The two curves together illustrate the effect of concentration-polarization produced in both directions and its direct explanation of the aging effect.

Similar confirmatory data were obtained by soaking one electrode in distilled water and another in $1 \mathrm{~N}$ potassium chloride, then immersing both in $0.05 \mathrm{~N}$ potassium chloride and comparing their potentials with that of an electrode aged in the $0.05 \mathrm{~N}$ solution.

The potential of silver-silver chloride electrodes is sensitive to very small polarizing currents, produced by as little as 0.1 to $0.2 \mathrm{mv}$ between 
a pair of them in a cell containing $0.05 \mathrm{~N}$ potassium chloride and having an internal resistance of about $250 \mathrm{ohms}$. This was shown by connecting a pair of closely agreeing thermal electrodes to a polarograph ${ }^{13}$ and photographically recording current-voltage curves. The total potential drop across the revolving potentiometer drum was fixed at $1.9 \mathrm{mv}$ by insertion of the proper resistance in the external battery circuit, so that each of the 19 turns of wire on the drum corresponded to only $0.1 \mathrm{mv}$. If no concentration-polarization occurred, the polarograms would show straight lines, in accordance with Ohm's law, as they did with a wire resistance in place of the cell. In the polarogram of figure 8, curve $A$ is the current-voltage curve beginning with 0 and

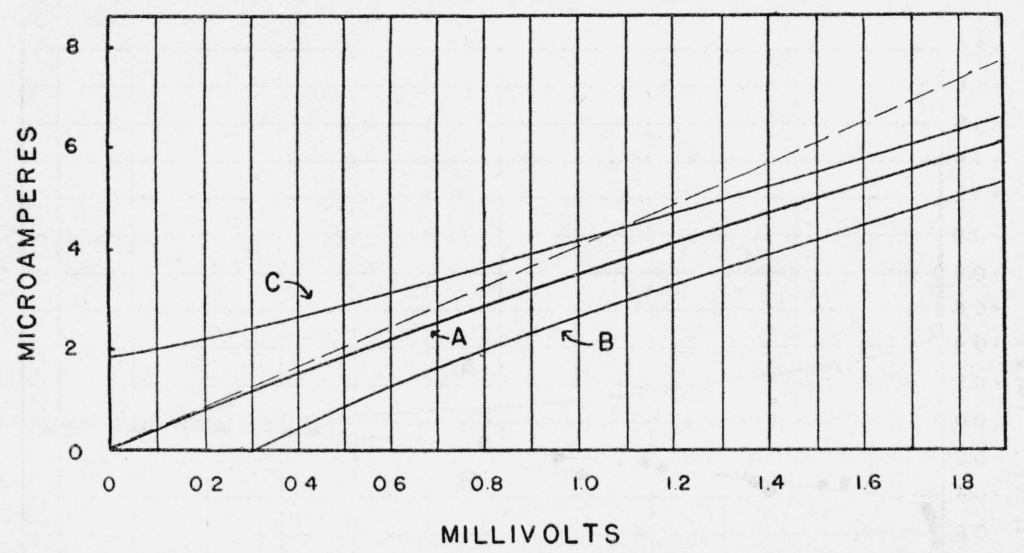

FiguRe 8.-Polarogram demonstrating concentration-polarization produced by minute currents between silver-silver chloride electrodes of the thermal type.

ending with $1.9 \mathrm{mv}$ across the two electrodes, which were initially of the same potential. The first part of the curve, up to about $0.1 \mathrm{mv}$, is a straight line corresponding to Ohm's law, which is shown by the dotted line. Beyond about $0.1 \mathrm{mv}$ the effect of concentration-polarization appears as an opposing emf causing the current to fall below the dotted line. Curve $B$ was taken as soon as curve $A$ was finished by simply starting again at 0 and increasing the potential difference again up to $1.9 \mathrm{mv}$. This time the electrodes at the start were polarized oppositely and exerted a counter emf to the applied potential difference. The current was therefore negative at the start, being due to the residual concentration-polarization, reached 0 at an applied potential difference of about $0.3 \mathrm{mv}$, where the emf of the residual concentration-polarization was equal and opposite to the applied potential difference, and then increased at a decreasing rate as additional concentration-polarization was developed. Curve $C$ was taken immediately after curve $B$ was photographed by reversing the electrode connections and going again from 0 to $1.9 \mathrm{mv}$. Here the applied potential difference and the emf of concentration-polarization are additive, thus producing a current greater than before, which increases at a decreasing rate as the initial concentration-polarization progressively decreases and approaches reversal. The polarogram thus confirms the explanation of the aging effect as a concentration-polarization, and affords a picture of its progress produced artifically, both forwards and backwards, by the passage of very small currents.

${ }^{13}$ J. Heyrovsky in Physikalische Methoden der Analytischen Chemie, II, 260 (Leipzig 1936). 
The significant effect of concentration-polarization on the potential of the silver-silver chloride electrode, and the requirement of sufficient aging time to attain concentration equilibrium within the porous silver chloride offer a possible explanation of why certain investigators have noted a drift in potential and reported the thermal-electrolytic type to be more positive than the thermal type ${ }^{14}$ of why others have discarded the electrolytic type as unreliable, ${ }^{15}$ and of differences in the values reported for the standard electrode potential of the silversilver chloride electrode. ${ }^{16}$

It was found in this work that if sufficient time is allowed, the electrolytic, thermal-electrolytic and thermal types finally come to agreement in potential within about $0.02 \mathrm{mv}$. The time required to attain this equilibrium depends on the porosity of the electrodes, the concentration and the stirring of the solution, and in some cases may be as long as 20 days. Agreement of electrodes within a set prepared at a given time is no criterion that their potential has come to equilibrium, since this agreement a few hours after preparation may be practically as good as later, when equilibrium has been established at a potential which may have changed by several tenths millivolt. Also, the rate of approach to equilibrium is often so slow as to be almost undetectable over a few hours time, even when a significant difference still exists between the measured and the equilibrium values.

In many measurements involving silver-silver chloride electrodes, the influence of concentration-polarization has been at least partially, even if unknowingly, compensated by the use of opposing electrodes of the same type prepared under the same conditions at the same time. Although the resulting error may be small in the case of such relative measurements, it may attain considerable significance in measurements where the standard electrode potential of silver-silver chloride is involved.

Washington, March 29, 1938.

14 C. K. Rule and V. K. La Mer, J. Am. Chem. Soc. 58, 2339 (1936)

${ }_{15} \mathrm{M}$. Randall and L. E. Young, J. Am. Chem. Soc. 50, 989 (1928). A. S. Afanasiev, J. Am. Chem. Soc. 52, $3477(1930)$.

${ }^{16} 0.2238$ v. A. A. Noyes and J. H. Ellis, J. Am. Chem. Soc. 39, 2532 (1917).

0.2234 v. G. A. Linhart, J. Am. Chem. Soc. 41, 1175 (1919).

0.2226 v. G. Scatchard, J. Am. Chem. Soc. 47, 641 (1925).

0.2228 v. G. Nonhebel, Phil. Mag. [7] 2, 1085 (1926).

0.2221 v. M. Randall and L. E. Young, J. Am. Chem. Soc. 50, 989 (1928).

0.2224 v. E. J. Roberts, J. Am. Chem. Soc. 52, 3877 (1930).

0.2223 v. W. R. Carmody, J. Am. Chem. Soc. 54, 188 (1932).

0.2224 v. H. S. Harned and R. W. Ehlers, J. Am. Chem. Soc. 54, 1350 (1932).

0.2221 v. Int. Crit. Tables 6, 332 (1929). 